\title{
Modern damage detection by using static assessment methods for efficient rehabilitation
}

\author{
F. Scherbaum ${ }^{1)}$, J. Mahowald ${ }^{1)}$, D. Waldmann ${ }^{1)}$, S. Maas ${ }^{1)}$, A. Zürbes ${ }^{2)}$ \\ ${ }^{1)}$ Faculté des Sciences, de la Technologie et de la Communication \\ Université du Luxembourg, Luxembourg, Luxembourg \\ ${ }^{2)}$ Fachbereich Technik, Informatik und Wirtschaft \\ Fachhochschule Bingen, Bingen, Germany
}

\begin{abstract}
The existing bridges become increasingly older, which leads to the fact that bridge inspections, in the future, will be even more important. The assessment of the remaining useful life of bridges and the damage detection, apart from the continuous supervision of a structure investigation and the assessment methods, as well, become more relevant. Normally, the above mentioned methods are costly and time consuming.
\end{abstract}

Therefore, the University of Luxembourg carries out a project to investigate an efficient application of different assessment methods, taking into account praxis relevant test conditions. Within the context of nondestructive testing methods and static assessment methods are analyzed and explained by the example of a two span box girder bridge. The presented bridge is a $102 \mathrm{~m}$ long prestressed concrete bridge, which was demolished after the performed tests due to a changed urban planning. Thereby the practicability of damage detections, by using static load tests, can be investigated. Within these test series the structure was damaged step by step, by artificial damage: with each damage scenario a part of the prestressed tendons were cut, which finally lead to a local cracking. By the analysis of the load-deformation-behavior, damages can be detected and located. A statement about the level of the damage can also be made.

\section{INTRODUCTION}

The existing bridges become increasingly older, which leads to the fact that bridge inspections will be more and more important in the future. But normally these inspections are time consuming and cost intensive. That is why the University of Luxembourg investigates non-destructive testing methods. As a part of this project the damage detection, by using an in-situ load test, was investigated at a real bridge in Luxembourg (Scherbaum \& Mahowald 2011b). By measuring the vertical deflection it is investigated, whether a clear detection of damage is possible.

\section{BRIDGE DESCRIPTION}

The investigated bridge is a two span prestressed concrete bridge with different span lengths (Figure 1 and Figure 2). The superstructure of the bridge is a prestressed box girder with 32 parabolic, 24 upper straight lined and 20 lower straight lined subsequently injected tendons. In 1987, 56 external prestressed steel cables were added into the box girder of the large field.

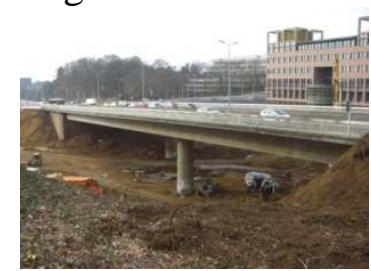

Figure 1. Side view of the bridge

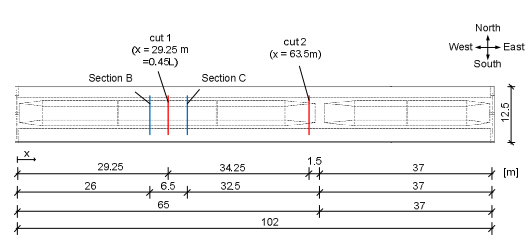

Figure 2. Longitudinal section of the bridge

\section{EXECUTED TEST PROGRAMME}

To simulate an increasing damage of the bridge the superstructure was damaged stepwise by four damage scenarios. Table 1 describes these damage scenarios. In each scenario the bridge was loaded and unloaded by using 38 steel beams, which illustrates an experimental load of $245 \mathrm{t}$ (Figure 3 \& Figure 4). Throughout the tests, the vertical deflection was measured by displacement transducers in section B and in section $\mathrm{C}$ (Figure 5) at the surface of the bottom plate of the box girder. Additionally to this, the vertical deflection was measured in 6 sections (sec- 
tion $\mathrm{A}$ to $\mathrm{F}$ ) along the bridge on the top of the superstructure (Figure 5) by a digital leveling.

Table 1. Description of the damage scenarios according to the cutting sections

\begin{tabular}{|c|c|}
\hline $\begin{array}{l}\text { Damage } \\
\text { scenario }\end{array}$ & Damage \\
\hline \# 0 & Undamaged State \\
\hline \# 1 & $\begin{array}{l}\text { Cutting straight lined tendons in the lower part of } \\
\text { the bridge at } 0.45 \mathrm{~L} \text { ( } 20 \text { tendons) }\end{array}$ \\
\hline \# 2 & $\begin{array}{l}\text { Cutting } 8 \text { straight lined tendons in the upper part } \\
\text { of the bridge over the pylon }\end{array}$ \\
\hline \# 3 & Cutting external tendons (56 wires) \\
\hline \# 4 & $\begin{array}{l}\text { Cutting } 16 \text { straight lined tendons in the upper part } \\
\text { of the bridge and also } 8 \text { parabolic tendons }\end{array}$ \\
\hline
\end{tabular}

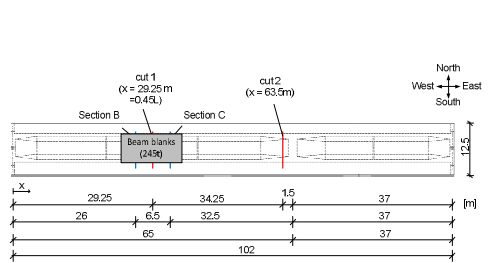

Figure 3. Position of the experimental load

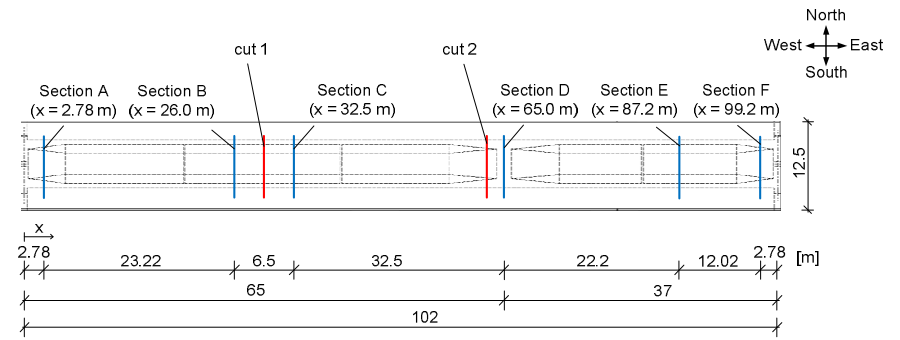

Figure 5. Position of the measurement sections

\subsection{Vertical deflection of the superstructure}

Figure 6 presents the vertical deflection measured by displacement transducers in section B and section C. The two lines in the upper part of the figure represent the vertical deflection. In the lower part of the figure temperature variations are illustrated.

It can be seen, that each loading and unloading step, in each damage scenario can be recognized by measuring the vertical deflection. Moreover, it can be observed that the vertical deflection increases with a strong damage (damages scenario \#1 and \#3). In these two scenarios also a crack formation in the bottom plate and in the sidewalls was observed. However, a small damage, like damage scenario \#2 does not really lead to an increase of the vertical deflection under load. In this damage scenario 8 tendons were cut, which did not lead to a new crack formation.

In Figure 6 it can also be identified, that the changing of the temperature leads to the deformation of the superstructure. In relation to the damage detection, it can be seen, that temperature changes can leads to a larger vertical deflection than damage scenario \#2.

\subsection{Comparison of displacement transducer and digital leveling}

The comparison of the digital leveling and the displacement transducer reveals that both systems illustrate nearly the same global behavior. In the loaded damage scenario \#3, a maximum deviation of 1.8 $\mathrm{mm}$ was measured between the digital leveling and the displacement transducer.

\section{CONCLUSION}

The static load test shows, that a damage which leads to a crack could be detected by measuring the vertical deflection. In damage scenario \#1 and \#3 the vertical deflection increases in relation to the undamaged state respectively to the previous damage scenario \#2. But it is important to know, that the influence of the temperature changing could even be higher than from a small damage. So this influence has to be considered in the analysis of the static load test. To be aware of the influences due to temperature, the deflection behavior of an undamaged structure should be analyzed for varying temperatures.

Also it is important to take into account the measuring accuracy of the different measuring systems.

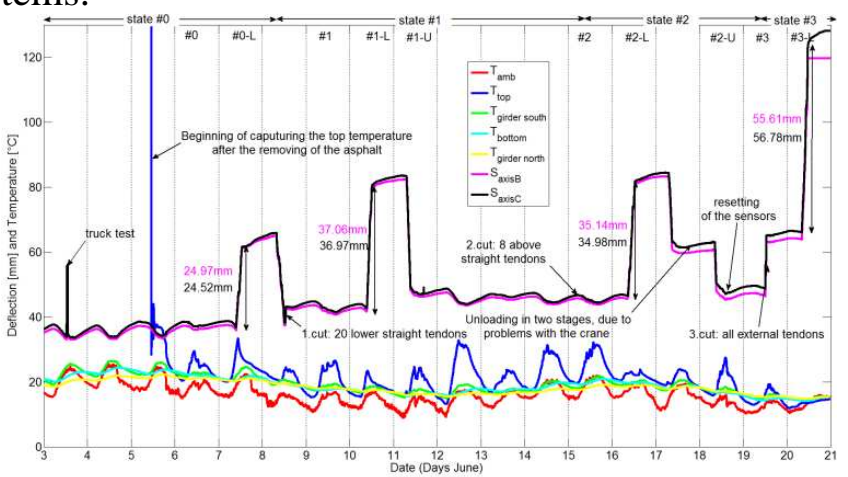

Figure 6. Vertical deflection in section $\mathrm{B}$ and $\mathrm{C}$ and temperature changes during the test period

\section{REFERENCES}

Bungard, V.; Walterin, M.; Waldmann, D.; Maas, S. \& Zuerbes, A. 2009. Comparison of static behaviour and nonlinear vibration characteristics of gradually damaged prestressed concrete slabs and reinforced concrete beams. Proceeding of the EVACES 09 conference. Wroclaw. Poland.

Bungard,V. 2010. Condition assessment of concrete structures and bridges using vibration monitoring in comparison to changes in their static properties. PhD-Thesis at the University of Luxembourg.

Gutermann, M. 2002. Ein Beitrag zur experimentell gestützten Tragsicherheitsbewertung von Massivbrücken. Dissertation. Technische Universität Dresden. Deutschland.

Mahowald, J. 2010 Report VII, University of Luxembourg.

Scherbaum, F. \& Mahowald, J. 2011b. Report Bridge Champangshiehl 2, University of Luxembourg. 